\title{
OCCIPITO-VERTEBRAL DISSOCIATION IN CONNECTION WITH EXTENSIVE CERVICAL SPINE MALSEGMENTATION IN A BOY WITH MÖBIUS SYNDROME
}

\author{
doi: $10.1590 / \mathrm{S1807-59322009001000016}$
}

Ali Al Kaissi, ${ }^{\mathrm{I}}$ Klaus Klaushofer, ${ }^{\mathrm{I}}$ Franz Grill ${ }^{\mathrm{II}}$

\section{INTRODUCTION}

Möbius ${ }^{1}$ syndrome has drawn attention to patients with congenital, non-progressive bilateral facial and abducens palsies. Anomalies of other cranial nerves, such as the hypoglossal (XII), craniofacial, or orofacial nerves, and limb malformations are often encountered in association with Möbius syndrome. The etiology and pathogenesis of Möbius syndrome are still controversial. Patients with Möbius syndrome are generally asymptomatic, but increasing age and injury may precipitate symptoms. Though most cases are sporadic, a few families with hereditary Möbius syndrome have been described..$^{1-4}$ Vertebral abnormalities are not a well-known feature in patients with Möbius syndrome. None the less, fusion of one or more contiguous segments results from the embryological failure in normal spine segmentation. ${ }^{5}$

This phenomenon is most likely the result of a decreased local blood supply during the third to eighth week of fetal development. ${ }^{6}$

In patients with vertebral fusion premature degenerative changes at adjoining motion segments are common, as this condition results in greater biomechanical stress in adjoining segments. Discal tears, rupture of transverse ligaments, fractures of the odontoid process and spondylosis are common consequences. Injuries to the atlanto-occipital region can range from complete atlanto-occipital or atlantoaxial dislocation to nondisplaced occipital condyle avulsion

\footnotetext{
${ }^{1}$ Ludwig-Boltzmann Institute of Osteology, Hanusch Hospital of WGKK and AUVA Trauma Center Meidling, $4^{\text {th }}$ Medical Department, Hanusch Hospital Vienna - Vienna, Austria.

II Orthopaedic Hospital of Speising, Paediatric Department - Vienna, Austria. Email: ali.alkaissi@osteologie.at

Tel.: 004319102186924
}

fractures. ${ }^{7-10}$ In the present case study, we detected pre- and postnatal injuries by analyzing the details of cervical spine ligamental and osseous disruptions by MRI imaging. The combination of occipito-vertebral dissociation (distractionseparation) associated with extensive cervical spine malsegmentation can be considered as a novel syndromic variant associated with Möbius syndrome.

\section{CLINICAL REPORT}

A 5-year-old boy was referred to the orthopedic department for clinical evaluation. He was the first child of healthy, non-consanguineous parents. At birth, his growth parameters were around the $50^{\text {th }}$ percentile. Maternal history was non-contributory (no history of spontaneous or elective abortions and/or prenatal exposure to misoprostol). Congenital facial diplegia was noted at birth together with ligamentous hyperlaxity and poor sucking, which led to feeding and choking problems. His subsequent development was slow. Walking was achieved at the age of 18 months, albeit with difficulty. Speech and language were significantly retarded, as were coordination skills. Conductive hearing loss was attributed to enlarged tonsils.

Examination at the age of 5 years showed growth around the $50^{\text {th }}$ percentile, facial diplegia, ptosis, and bilateral abducens nerve palsy with retraction of the bulb on lateral gaze. Limb abnormalities included partial syndactyly of the $2^{\text {nd }}, 3^{\text {rd }}$, and $4^{\text {th }}$ fingers and partial syndactyly of the $3^{\text {rd }}, 4^{\text {th }}$, and $5^{\text {th }}$ toes. The latissmus dorsi, trapezius, and pectoralis muscles were hypoplastic. The lower limbs demonstrated genu valgum (knock-knees). Thoracic kyphosis associated with painful and restricted mobility of the neck was noted. Neurological examination evoked suboccipital and neck pain, and the upper arms were weak. Some limitations were 
noted in cervical motion, especially with respect to rotation and lateral bending.

The cardiologic examination was normal, as were the renal ultrasound scans. Laboratory studies demonstrated normal white and red blood cell and platelet counts and normal calcium, phosphorus, and alkaline phosphatase levels. Urine amino acids and mucopolysaccharides were normal, and the patient had a normal karyotype.

In view of the seriousness of the patient's cervical lesions, exploratory procedures were not recommended and dynamic X-rays were considered as too dangerous to perform. A lateral craniocervical radiograph showed that, throughout the cervical spine, there was extensive fusion of both the anterior and posterior elements in association with occipito-vertebral dissociation (arrow) (Figure 1). MRI imaging revealed increased discontinuity/disruption of the ligaments effectively causing the observed occipito-vertebral dissociation (Figure 2).

Initial treatment of the patient involved immobilization for variable lengths of time, followed by re-evaluation by MRI imaging. Awareness and monitoring of the complications associated with Möbius syndrome should be instituted.

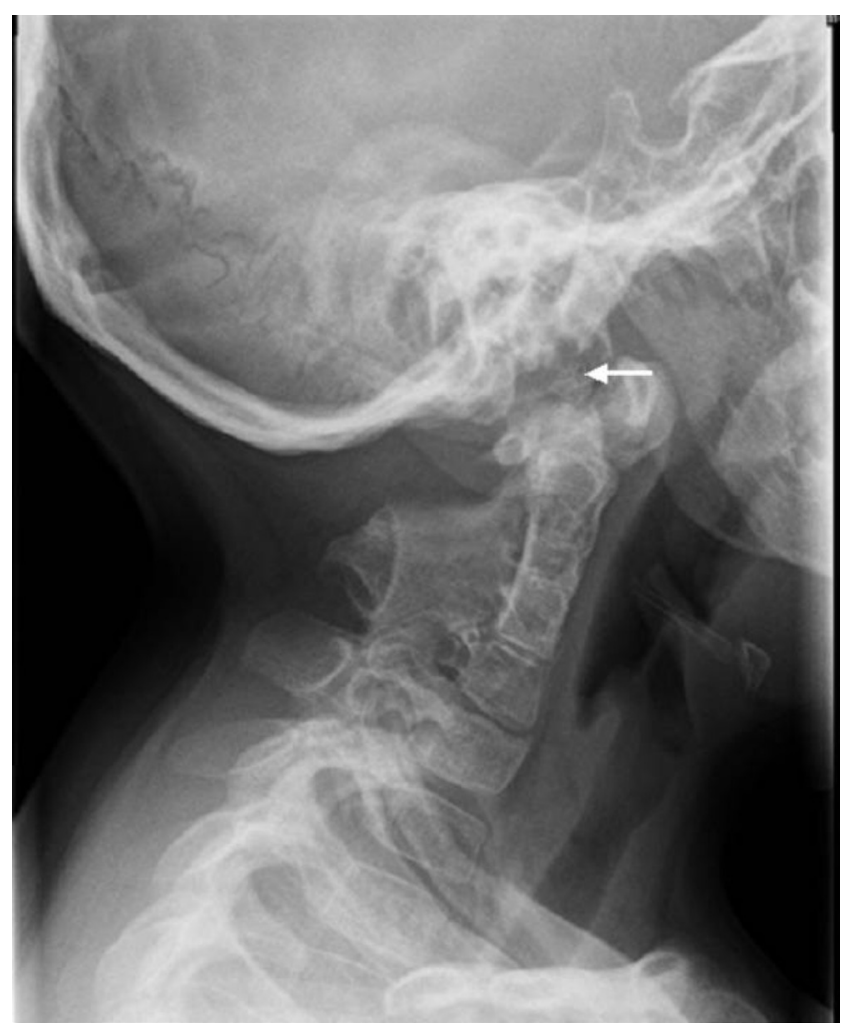

Figure 1 - Lateral radiograph showing atlanto-occipital dissociation (more than $12 \mathrm{~mm}$ between the basion and dens with a space clearly visible between the cranium and $\mathrm{C} 1$ ). The radiograph demonstrates extensive fusion throughout the cervical spine of both the anterior and posterior elements. Note the extensive fusion of the vertebral bodies of $\mathrm{C} 2 / 3-4$ and the total fusion of the spinous processes of C2-6. Also, note the detached os terminale (arrow)

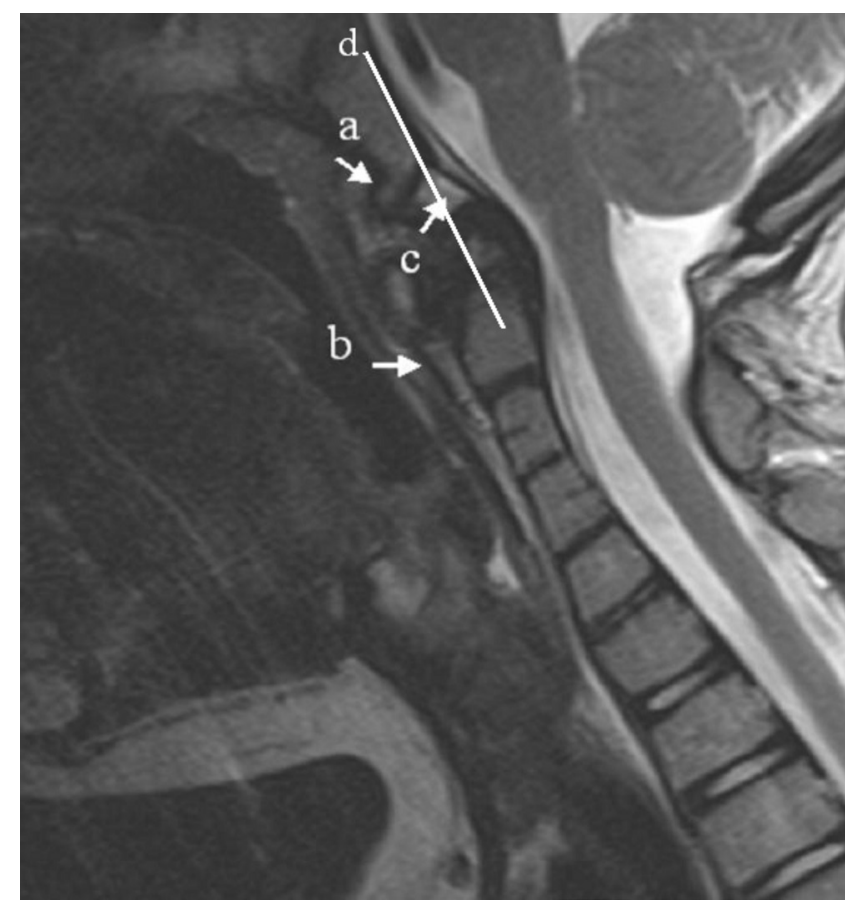

Figure 2 - Sagittal MRI imaging revealing discontinuity of the cervical ligaments. Note the disruption of the anterior atlanto-occipital ligament, which connects the lower anterior clivus with the anterior aspect of the body of $\mathrm{C} 2$, as visualized by the superior continuation of the anterior longitudinal ligament. In addition, disruption of the anterior longitudinal ligament is evident (arrow-b). Note the dislocated atlas (arrow-c) and compression of the dura mater space. Line (d) represents the Wachenheim-clivus line (a method to evaluate craniocervical abnormalities). The line is drawn along the posterior aspect of the clivus, toward the odontoid process (OP). In normal subjects, the line is tangential to the posterior aspect of the OP. In contrast, in our patient, this line intersects the anterior aspect of the OP

\section{DISCUSSION}

Möbius syndrome is characterized by non-progressive, congenital facial and abducens palsy and can be associated with other cranial nerve palsies, orofacial dysmorphisms, and limb or axial malformations. ${ }^{1}$

A number of reports have evaluated the extent of the malformations that occur in Möbius patients. Larrandaburu et al. ${ }^{11}$ reported a family in which a 14-year-old girl had a combination of Poland and Möbius syndromes and a maternal aunt had features only of Möbius syndrome. Hennekam ${ }^{12}$ reported a family in which one individual had a Poland-associated anomaly, another had a hemifacial microsomia, and yet another had a neural tube defect. An etiology of vascular origin was hypothesized. In support of this hypothesis, Lipson et al. ${ }^{13}$ reported the cases of two infants; one had "classical Möbius syndrome" but without any hand abnormalities, and the other had hypertonic cerebral palsy and was shown postmortem to have hypoxic/ ischemic lesions in the caudate nucleus, putamen, and striatum. In both of these cases the mothers had suffered trauma during pregnancy at 18 and 14 weeks of gestation, 
respectively, resulting in rupture of the spleen and severe hypotension. Pedraza et al. ${ }^{14}$ evaluated the MRI findings of three patients with Möbius syndrome. MRI scans revealed brainstem hypoplasia with straightening of the fourth ventricle floor indicating an absence of the facial colliculus. Verzijl et al. ${ }^{4}$ described Möbius syndrome as a condition of rhombencephalic maldevelopment that includes Duane retraction syndrome (34\%), conjugated horizontal gaze palsy (48\%), congenital fibrosis of the extraocular muscles (9\%), and lingual involvement (77\%). Dysfunction of the palate and pharynx occurred in $56 \%$ of cases, and respiratory problems, incoordination, and other features were thought to originate in the lower brain stem. None of the abovementioned case studies reported spinal malformations, as observed in our patient.

Facial weakness, Duane anomaly, and vertebral abnormalities are a well-known set of malformation complexes that occur in association with Goldenhar, ${ }^{15}$ Wildervanck, ${ }^{16}$ and Hanhart syndromes. ${ }^{17}$ The overall clinicoradiographic features of our patient did not fit any of these syndromic entities.

The craniocervical junction is a complex articulation consisting of multiple ligamentous structures. In normal individuals, the anterior third of the cervico-occipital canal is occupied by the dens axis and the middle third by the spinal cord, which, once infringed upon, can result in spinal cord injury. The combination of occipito-vertebral dissociation and hypermobility at the atlantoaxial junction, secondary to extensive malsegmentation of the upper cervical vertebras, uniquely predisposes patients with syndromic malformation complexes to various serious neurological deficits, as observed in our patient. The most common of these neurological deficits is myelopathy, which results in quadriplegia, paraplegia, weakness of the lower limbs, crossed paralysis, or hemiplegia. Other manifestations include nuchal pain and stiffness, foramen magnum syndrome, or sudden death due to compression of vital structures at the cervicomedullary junction. ${ }^{8,9,18}$

Here, we describe a patient with Möbius syndrome in order to demonstrate the necessity, when appropriate, to detail the anatomy of the malformed occipito-vertebral junction and to signify the pathophysiology of the associated cervical spine malsegmentation.

\section{REFERENCES}

1. Mobius PJ. Ueber angeborene doppelseitige Abducens-FacialisLahmung. Munch Med Wochenschr. 1888;35:91-4.

2. Baraitser M. Genetics of Moebius syndrome. J Med Genet. 1977;14:415-

3. St Charles S, DiMario FJ Jr, Grunnet ML. Mobius sequence: further in vivo support for the subclavian artery supply disruption sequence. Am J Med Genet. 1993;47:289-93.

4. Verzijl HT, van der Zwaag B, Cruysberg JR, Padberg GW. Mobius syndrome redefined: a syndrome of rhombencephalic maldevelopment. Neurology. 2003;61:327-33.

5. Klippel M, Feil A. Un cas d'absence des vertebres cervicales. Avec cage thoracique remontant jusqu'a la base du crane (cage thoracique cervicale). Nouv Iconog Salpetriere. 191225:223-50.

6. Guebert GM, Rowe LJ, Yochum TR, Thompson JR, Masia CJ Congenital anomalies and normal skeletal variants. In: Yochum TR, Rowe LJ, eds. Essentials of Skeletal Radiology. 3rd ed. Baltimore: Lippincott Williams \& Wilkins.2005:257-403.

7. Harris Jr. Carson G, Wagner L, Kerr n. Radiologic diagnosis of Traumatic Occipitovertebral Dissociation: Comparison of Three Methods of Detecting Occipitovertebral Relationships on Lateral Radiographs of Supine Subjects. AJR. 1994;162:887-92.

8. Smoker WR. Craniovertebral junction: normal anatomy, craniometry, and congenital anomalies. RadioGraphics. 1994;14:255-77.

9. Yamashita Y, Takahashi M, Sakamoto Y, Kojima R. Atlantoaxial subluxation. Radiography and magnetic resonance imaging correlated to myelopathy. Acta Radiol. 1989;30:135-40.
10. Deliganis AV, Baxter AB, Hanson JA, Fisher DJ, Cohen WA, Wilson AJ, et al. Radiologic spectrum of craniocervical distraction injuries. Radiographics. 2000;20 Spec No:S237-50.

11. Larrandaburu M. The occurrence of Poland and Poland-Moebius syndromes in the same family: further evidence of their genetic component. Clin Dysmorphol 1999;8:93-9.

12. Hennekam RCM. Familial liability to intrauterine vascular impairments. Pediatrics 1990;86:326-7.

13. Lipson AH, Gillerot Y, Tannenberg AEG, Giurgea S. Two cases of maternal antenatal splenic rupture and hypotension associated with Moebius syndrome and cerebral palsy in offspring. Eur J Pediatr. 1996;155:800-4.

14. Pedraza S, Gámez J, Rovira A, Zamora A, Grive E, Raguer N, et al MRI findings in Mobius syndrome: correlation with clinical features. Neurology 2000;55:1058-60.

15. Cohen MM Jr, Rollnick BR, Kaye CI. Oculoauriculovertebral spectrum: an updated critique. Cleft Palate J. 1989;26:276-86.

16. Balci S, Oguz KK, Firat MM, Boduroglu K. Cervical diastematomyelia in cervico-oculo-acoustic (Wildervanck) syndrome: MRI findings. Clin Dysmorphol. 2002;11:125-8.

17. Al Kaissi A, Grill F, Safi H, Ben Ghachem M, Ben Chehida F, et al Craniocervical junction malformation in a child with Oromandibularlimb hypogenesis-Möbius syndrome. Orphanet J Rare Dis. 2007;8;2:2.

18. Dickman CA, Rekate H, Sonntag VK, Zabramski JM. Pediatric spinal trauma: vertebral column and spinal cord injuries in children. Pediatric Neuri. 1989;237-56 